\title{
Tuberous Sclerosis Complex: A Case Report
}

\author{
Aunur Rofiq ${ }^{1}$, Lita Setyowatie ${ }^{2}$, Aninda Fitri Nugrahani ${ }^{3}$ \\ 1,2,3 Department of Dermatology and Venereology, Faculty of Medicine, Universitas \\ Brawijaya / dr. Saiful Anwar Regional General Hospital, Malang, Indonesia \\ Telephone: +62818382829 \\ Email : qiphor@yahoo.com
}

Received : Sept $9^{\text {th }}$ 2019. Revised : Oct $1^{\text {th }}$ 2019. Published : Dec $23^{\text {th }} 2019$

DOI : https://doi.org/10.22219/sm.Vol15.SMUMM2.9935

\begin{abstract}
Tuberous Sclerosis Complex (TSC) is an autosomal dominant inherited neurocutaneous disorder. Tuberous Sclerosis Complex is caused by mutations in tumor suppressor gene (TSC), both TSC1 and TSC2. In approximately two-thirds of cases neither parent has signs of TSC and the disease is caused by a de novo mutation. Tuberous Sclerosis Complex is classically identified by the Vort's triad in the presence of angiofibroma, mental retardation, and epilepsy. A 17-year-old woman with a major complaint of a facial bump that appeared at birth and got bigger when she reached puberty. There are white patches on the patient's body from birth. On the scalp obtained the presence of skin color plaque, while at the back and right knee obtained shagreen patch. Patientwas diagnosed with epilepsy and mental retardation by the pediatric department. No family history has the same complaints as patient. Histopathologic examination of facial bumps taken by shaving biopsy suggests the presence of hemangiomas. Based on the clinical diagnostic criteria from International Tuberous Sclerosis Complex Consensus Conference 2012, the patient meets two major criteria, macular hypopigmentation and shagreen patch so it is included in "definite diagnosis".
\end{abstract}

Keywords: tuberous sclerosis complex, hemangioma, mental retardation, epilepsy.

Copyright (C) 2019, First Author et al This is an open access article under the CC-BY-SA license

\section{INTRODUCTION}

Tuberous Sclerosis Complex (TSC) also known as Epiloia or Bourneville-Pringle Disease is an autosomal dominant neurocutaneous syndrome with varying clinical expression (Rodrigues et al, 2012). The incidence of TSC is estimated to be 1: 6000 live births, although the exact incidence rate is likely to be higher due to the presence of undetectable cases mild (Kwiatkowski et al, 2005 ;Staley et al, 2011). Tuberous Sclerosis Complex is caused by mutations in tumor-suppressor gene, both TSC1 and TSC2 (Kwiatkowski et al, 2005).Classically identified by the Vort's triad, ie, facial angiofibroma, mental retardation, and recurrent epilepsy, no more than $30-40 \%$ of TSC-affected individuals who have all three clinical manifestations (Darling et al, 2012). 
CASE

The 17-year-old girl with the chief complaint of multiple bumps on her face. The bump firstly appearred when the she was 1 year old. The bump originally was just as big as pimples and multiplied and getting larger when she was 13 years old. The bump does not painful or itchy, but sometimes bleed when she rubs it. Patients were advised to operate the bump but the her parents refused because the bump was still small and unobtrusive.

She often had seizures. The first seizure when she was 3 months old. Seizures appearred without a fever. Patients routinely take phenytoin until 1 year of age. She had seizures almost daily. At the time of her first menstrual period she had a longer seizure than before. The patient then received additional medication, topiramate.

She has lumps on his gums. The lump just appeared about 4 years ago. The lump also does not hurt or bleed easily. Patients also have white patches on the body since birth. The patches are neither bigger nor multiplied. Patches also do not itchy.

No similar complaints were found to other patient's family members. She had delay in growth and development. Patients never go to school, can not speak and depend on their parents for daily activities.

Her general condition was good. Vital signs and laboratory checks were within normal limits. Dermatologic examination of the face there were multiple papules and hyperpigmented nodules with irregular shapes, smooth surfaces, and varying sizes. On her gingiva there were erythematous nodules with a smooth surface. On her the posterior side of the scalp there were skin colored plaque with an irregular shape. On her anterior trunk there were hypopigmentation macules and patches, well defined, irregular shape. Examination of the posterior trunk revealed hyperpigmentation papules, irregular shape, smooth surface, multiple, vary in size and also there were erythematous plaque, ill defined, irregular shape. On her left arm, thighs and left limbs there were hypopigmentation macules and patches, well defined, irregular shape. On her right thigh there were hypopigmentation macules, well defined, irregular shape, multiple with varying sizes. There were also erythematous plaque, ill defined, irregular shape, hypopigmented papules, smooth surface, multiple with varying sizes. On her nails of the hands and feet there were nail hyperkeratotic in digiti I left hand, digiti I, III, V right foot, and digiti IV, V left foot. 


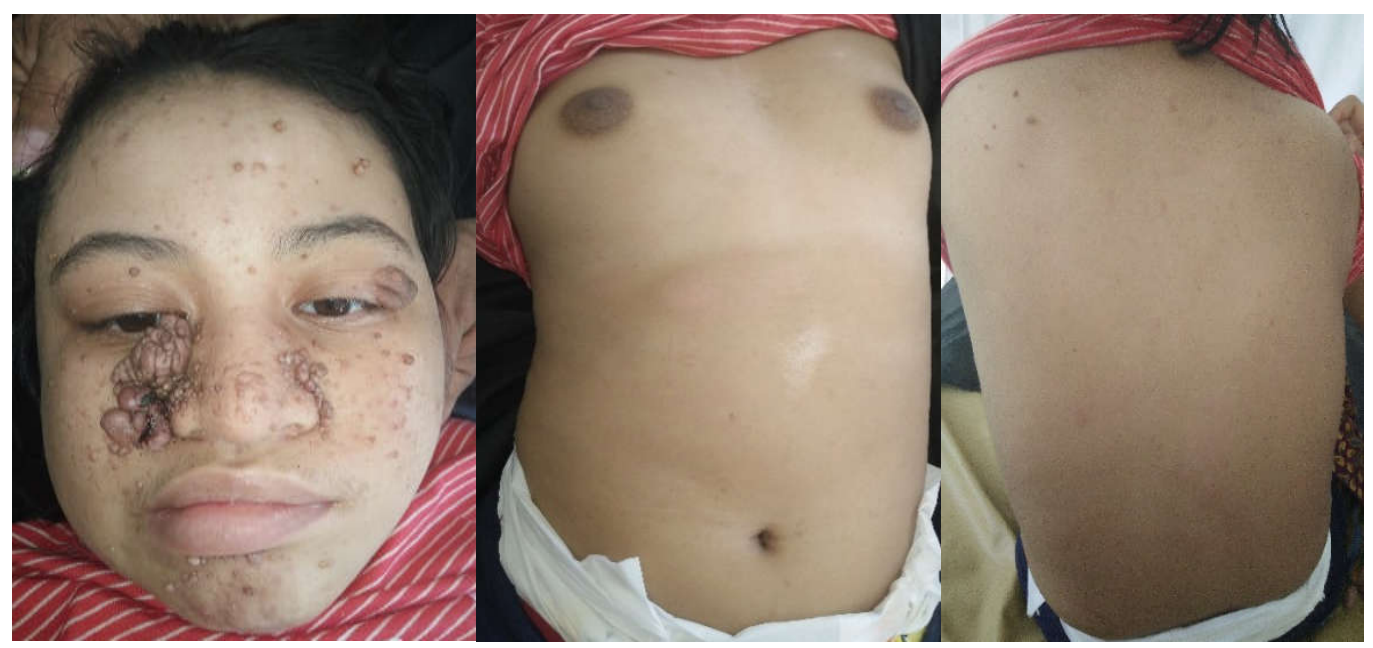

Figure 1. Multiple hyperpigmented papules and nodules with irregular shapes, smooth surfaces, and varying sizes on the face. Hypopigmented macules and patches, well defined, irregular shape on the anterior trunk. Erythematous plaque, ill defined, irregular shape on the posterior trunk

CT scan examination obtained multiple mass with calcification in the midline of the frontal region, left lateral intra ventricle, right lateral ventricle of anterior cornususpcysticercus dd echinococcus; multiple lesions of cortex hypodens subcortical left temporal lobe, left occipital, left frontal lobe subcortical, right parietal lobe cortical susp ulcerative early cyst; and cerebral edema. The EEG examination showed potential epileptogenicity in the right central and left temporal region with a mild diffuse encephalopathy. Abdominal ultrasound examination indicates calcification of the dextra and spinal cortex and splenomegaly. Echocardiographic examination suggests a period (calcification) in the interventricular septum and the interatrial septum. Histopathologic examination of the lump on the face provides a picture that suits the capillary et cavernous hemangioma.

Tuberous Sclerosis Complex (TSC) is caused by mutations in tumor-suppressor genes, both TSC1 and TSC2, although in 15\% of cases there is no mutation. Up to two-thirds of patients were not found to have a history of parents with the same complaint, which indicates high rates of spontaneous mutations (Sancak et al, 2005). In this case report TSC occurs in girls where no history of the same disease occurs in the patient's family.

The genetic diagnosis criteria for TSC is when there is a mutation in both TSC1 and TSC2 taken from normal tissue genes. The normal results do not rule out the diagnosis of TSC. Tuberous Sclerosis Complex is classically identified by the Vort's triad in the presence of angiofibroma, mental retardation, and epilepsy. Clinical diagnostic criteria are divided into two criteria, major and minor criteria. This criteria was called as TSC Consensus Conference Clinical Diagnostic Criteria. Two major criteria or one major with $\geq 2$ minor are defined as "definite diagnosis". Whereas only one major or $\geq 2$ minor is defined as "possible diagnosis" (Northrup et al, 
2013). Based on this criteria this patient was "definite diagnosis" because she has hipopigmented macules and Shagreen patch.

Table 1. Diagnostic Criteria for Tuberous Sclerosis Complex from International Tuberous Sclerosis Complex Consensus Conference 2012 (Northrup et al, 2013).

\begin{tabular}{|c|c|}
\hline Major Criteria & Minor Criteria \\
\hline $\begin{array}{l}\text { 1. Hypopigmented macules }(\geq 3 \text {, diameter } \\
\text { at least } 5 \mathrm{~mm} \text { ) }\end{array}$ & $\begin{array}{l}\text { 1. Skin lesions "Confetti" } \\
\text { 2. The tooth enamel basin (> 3) }\end{array}$ \\
\hline $\begin{array}{l}\text { 2. Angiofibroma }(\geq 3) \text { or fibrous cephalic } \\
\text { plaque }\end{array}$ & $\begin{array}{l}\text { 3. Intraoral fibroma }(\geq 2) \\
\text { 4. Retinal achromic patch }\end{array}$ \\
\hline 3. Ungual fibroma $(\geq 2)$ & 5. Multiple renal cysts \\
\hline 4. Shagreen patch & 6. Nonrenal hartartoma \\
\hline 5. Multiple retinal Hamartomas & \\
\hline 6. Dysplasia of the cortex & \\
\hline 7. Subependimal nodules & \\
\hline 8. Giant cell subependimal astrocytoma & \\
\hline 9. Heart Rhabdomyoma & \\
\hline 10. Lymphangioleiomyomatosis (LAM) & \\
\hline 11. Angiomyolipomas (AMLs) & \\
\hline
\end{tabular}

Neurologic clinical manifestations of TSC are epilepsy, cognitive delay, and autism. Epilepsy can occur in $90 \%$ of cases. The earlier onset of epilepsy, the greater the recurrence rate and cognitive delay are also more severe (Samir et al, 2011). In this patient the initial history of seizures occurs at 3 months of age and continues to recur even if the patient had received treatment. Patients can walk at the age of 1.5 years and can not speak anything until now.

TSC also affects teeth and gum tissue. Fibroma gingiva accounts for about $36 \%$ of adult patients and rarely found in children younger than 11 years. The most common sites are in the anterior gingiva and the lesions was meat-colored or erythematoses (Darling et al, 2012; Martelliet al, 2010). It is estimated that about $30-50 \%$ of patients receiving phenytoin therapy exhibit significant gingival changes (Modéer et al, 2000).

Histopathologic examination of facial nodules consistent to capillary et cavernous hemangioma. Patient was planned to excision with general anesthesia so the patient is consulted to the Plastic Surgery section.

The prognosis for the individual patient depends on disease expressivity. Some individuals have a normal life span with few medical complications. The causes of premature death include renal failure, intractable seizures, obstructive hydrocephalus, cardiac outlow obstruction, arrhythmia, respiratory failure, pneumothorax, and hemorrhage from an aneurysm or a tumor, 
especially AMLs (Darling et al, 2012).The TSC Consensus Conference of 1998 recommended ultrasound scanning of the kidneys every 1-3 years in older children and adults with TSC to assess the development and progression of AMLs. Computed tomography scans of the chest should be performed once in asymptomatic patients and every 6-12 months when symptoms occur. Echocardiography should be performed at any age whenever cardiac symptoms occur. CT or MRI should be performed every 1-3 years in childhood and less often in adults to facilitate early detection and possible treatment. Frequency of EEG depends on the course of epilepsy (Borkowska, et al, 2011).

\section{CONCLUSION}

A case of tuberosclerosis complex has been reported in 17-year-old girl. She had growing bump on her face which getting bigger and multipled when she was of her puberty, white patches that appearred from birth, recurrent epilepsy and mental retardation. Based on the clinical diagnostic criteria, there are two major criteria, hypopigmented macules and shagreen patch to be included in "definite diagnosis". Patient was planned to excision with general anesthesia so the patient is consulted to the Plastic Surgery section.The prognosis for the individual patient depends on disease expressivity. Some individuals have a normal life span with few medical complications.

\section{REFERENCES}

Borkowska, J., Schwartz, R. A., Kotulska, K., \&Jozwiak, S. (2011). Tuberous sclerosis complex: tumors and tumorigenesis. International journal of dermatology, 50(1), 13-20.

Darling,T. N. Tuberous Sclerosis Complex. Goldsmith, LA et al (ed). (2012) In Fitzpatrick's Dermatology in General Medicine. New York : Mc Graw Hill.

Kwiatkowski, D. J., \& Manning, B. D. (2005). Tuberous sclerosis: a GAP at the crossroads of multiple signaling pathways. Human molecular genetics, 14(suppl_2), R251-R258.

Martelli, H., Lima, L. S., Bonan, P. R. F., \& Coletta, R. D. (2010). Oral manifestations leading to the diagnosis of familial tuberous sclerosis. Indian Journal of Dental Research, 21(1), 138.

Modéer, T., Domeij, H., Anduren, I., Mustafa, M., \&Brunius, G. (2000). Effect of phenytoin on the production of interleukin- 6 and interleukin-8 in human gingival fibroblasts. Journal of oral pathology \& medicine, 29(10), 491-499.

Northrup, H., Krueger, D. A., Roberds, S., Smith, K., Sampson, J., Korf, B., ... \& de Vries, P. (2013). Tuberous sclerosis complex diagnostic criteria update: recommendations of the 2012 International Tuberous Sclerosis Complex Consensus Conference. Pediatric neurology, 49(4), 243-254.

Rodrigues, D. A., Gomes, C. M., \& Costa, I. M. C. (2012). Tuberous sclerosis complex. Anais brasileiros de dermatologia, 87(2), 184-196. 
Samir, H., Ghaffar, H. A., \& Nasr, M. (2011). Seizures and intellectual outcome: clinico-radiological study of 30 Egyptian cases of tuberous sclerosis complex. european journal of paediatric neurology, 15(2), 131-137.

Sancak, O., Nellist, M., Goedbloed, M., Elfferich, P., Wouters, C., Maat-Kievit, A., ... \& van den Ouweland, A. (2005). Mutational analysis of the TSC1 and TSC2 genes in a diagnostic setting: genotype-phenotype correlations and comparison of diagnostic DNA techniques in tuberous sclerosis complex. European Journal of Human Genetics, 13(6), 731.

Staley, B. A., Vail, E. A., \& Thiele, E. A. (2011). Tuberous sclerosis complex: diagnostic challenges, presenting symptoms, and commonly missed signs. Pediatrics, 127(1), e117-e125. 